\title{
Prevalence and associated factors of HBV infections among HIV-infected HAART receiving mothers and their exposed infants in Nairobi, Kenya
}

\begin{abstract}
Mother-to-child transmission (MTCT) of Hepatitis B virus (HBV) is responsible for more than one third of chronic HBV infections worldwide. Antiretroviral therapy (ART) naïve HBV/HIV co-infected mothers have a high tendency of transmitting the two viruses. This study aimed to determine prevalence \& predisposing factors of HBV infections among HAART-receiving HIV-infected mothers and their exposed infants. A structured questionnaire was used to capture socio-demographic data and factors associated with HBV infections. As 4_ml sample of paired whole blood obtained from HIV positive mothers \& their exposed infants was analyzed for Hepatitis B surface antigen (HBsAg) using both rapid and Enzyme-linked immuno sorbent assay (ELISA) tests. HBsAg positive samples were further screened for HBV envelope antigen ( $\mathrm{HBeAg}$ ) using ELISA. HBsAg positive samples with both ELISA and rapid tests were subjected to a nested Polymerase chain reaction (PCR) targeting the preS1 region. A total of 534 HIV-infected mothers - infant pairs were recruited. Mean age of mothers was 31.2 years (SD 5.4 years) and infants' median age of 6 months (IQR 3-10 months). 502 (94\%) of the mothers were taking TDF/3TC/ NVP and 32(6\%) were on AZT/3TC/NVP or EFV. 19 of $534(3.6 \%)$ mothers were $\mathrm{HBV}$ positive by both HBsAg rapid and ELISA tests. All $19 \mathrm{HBsAg}$ positive samples tested $\mathrm{HBeAg}$ negative. 12 of the $19 \mathrm{HBsAg}$ positive samples also tested positive on PCR targeting the preS1 gene. All infants' samples tested HBV negative with all tests. History of dental surgery was associated with increased rate of HBV infection (OR $3.3(95 \% \mathrm{CI}$ 1.1-9.6). In this population of HIV-infected pregnant mothers, our observations suggest that the HAART regimen received by them may have prevented vertical transmission of HBV infections to exposed infants.
\end{abstract}

Keywords: Hepatitis B Virus infection, HIV-Infected Mother -infant pair, Highly active antiretroviral therapy, Predisposing factors
Volume 5 Issue 5 - 2017

\begin{abstract}
James Mburu Kang ethe, ${ }^{7}$ Rebecca Waihenya, ${ }^{2}$ Onesmus Gachuno, ${ }^{3}$ Kenneth Mutai, ${ }^{4}$ Musa Otieno, ${ }^{5}$ James Gitau Komu, ${ }^{6}$ Hilda Mesa, ${ }^{7}$ Raphael M wamtsi Lwembe' 'Kenya Medical Research Institute, Center for Virus Research, Kenya

'Department of Zoology, Jomo Kenyatta University of Agriculture and Technology Nairobi, Kenya

${ }^{3}$ Department of Obstetrics and Gynecology, University of Nairobi, Nairobi, Kenya

${ }^{4}$ Kenyatta National Hospital, Comprehensive Care Center, Kenya

${ }^{5}$ Kenya Medical Research Institute, Center for Microbiology Research, Kenya

${ }^{6}$ Department of Medical Laboratory Sciences, Jomo Kenyatta University of Agriculture and Technology, Kenya 7 Institute of Tropical Medicine and Infectious Diseases, Jomo Kenyatta University of Agriculture and Technology, Kenya
\end{abstract}

Correspondence: Raphael M wamtsi Lwembe, Centre for Virus Research, Kenya Medical Research Institute, P.O Box 54840-00200, Kenya, Tel +2547/8876976,

Email rlwembe@yahoo.com,rlweme@kemri.org

Received: March 03, 2017 | Published: June 15, 2017
Abbreviations: MTCT, Mother to Child Transmission; PMTCT, Prevention of Mother-to-Child Transmission; HBV, Hepatitis B virus; HIV, Human Immunodeficiency Virus; ART, Antiretroviral Therapy; HAART, Highly Active Antiretroviral Therapy; ELISA, Enzyme-Linked Immunosorbent Assay; HBsAg, Hepatitis B surface Antigen; HBeAg, Hepatitis B Envelope Antigen; PCR, Polymerase Chain Reaction; TDF, Tenofovir; 3TC, Lamivudine; NVP, Nevirapine; AZT, Zidovudine; EFV, Efavirenz; SSA, Sub Saharan Africa; IDU, Injection Drug Users; KNH, Kenyatta National Hospital; KEMRI, Kenya Medical Research Institute; EDTA, Ethylamine Tetra Acetic Acid; NAAT, Nucleic Acid Amplification Technique

\section{Introduction}

Chronic hepatitis B virus (HBV) infection is the leading cause of end-stage liver disease worldwide. In $2015,3.61 \%$ of the population was infected with HBV globally and $8.83 \%$ in the Sub Saharan African (SSA) region. ${ }^{1}$ Within the Southern and Eastern African region, the prevalence ranges between $2-8 \% .^{1}$ A previous study in Ethiopia reported $3.8 \%$ of pregnant women were infected with HBV. ${ }^{2}$ Studies in Kenya have shown HBsAg prevalence of $8.8 \%$ in the general population with a wider range in urban areas between $8-30 \%{ }^{1}$ Another study in pregnant women attending antenatal care in a tertiary hospital in Kenya showed that $4.2 \%$ were HBV-infected. ${ }^{3}$ Kenya is one of the HIV infection hotspots in SSA and high prevalence has been reported in women. ${ }^{4} \mathrm{HIV} / \mathrm{HBV}$ co-infection is common in HIV type-1-infected individuals with a prevalence ranging from $6 \%$ to $20 \%{ }^{5,6}$ Studies have reported a wide range of HIV/HBV co-infection from $1.5 \%$ in Cameroon ${ }^{7}$ to $19 \%$ in Ethiopia. ${ }^{2}$ Similar findings were reported in India where $4.6 \%$ of the HIV-infected pregnant women had HBV co-infection. ${ }^{8}$

History of blood transfusion is one of the risk factors associated with HBV infection. A study in Ethiopia found that pregnant women who had a previous history of blood transfusion were about four times more at risk of HBV infection. ${ }^{2,7}$ Injection drug users (IDUs), body piercing and tattooing have also been linked to HBV infection due to sharing of contaminated objects. Sharing of needles among IDUs has been shown to highly contribute to transmission of HIV and HBV with a study showing a HBV prevalence of $9.6 \%$ among the IDUs. Also, body tattooing increased the risk of HBV infection six fold. ${ }^{9}$ HBV screening in resource limited settings in HIV-infected mothers is rarely done despite the potential of transmission to their infants. A study in Australia found out HBV transmission rate of $2.9 \%$ in HBVexposed infants. ${ }^{10}$ This study was set to investigate the transmission of $\mathrm{HBV}$ infections from HIV-infected mothers receiving HIV HAART to their exposed infants.

\section{Materials and methods}

\section{Study area}

The study was carried out at the Kenyatta National Hospital (KNH). $\mathrm{KNH}$ is situated in Nairobi's South-western zone approximately 5 $\mathrm{km}$ from the Nairobi City Centre. Sample analysis was done at the University of Nairobi; Pediatrics department and Kenya Medical Research Institute (KEMRI) centre for virus research respectively. 


\section{Study population}

Approximately 400 mothers of reproductive age, who are HIV positive, are normally enrolled into a PMTCT program for HIV care and treatment every month. A total of 534 HIV-infected women attending PMTCT care at KNH were included in this study. All the enrolled mothers were on HAART and had undetectable HIV viral load. A total of 19 infants whose mothers were HBsAg positive were included. The women included those who delivered in $\mathrm{KNH}$ and those who delivered elsewhere and opted to seek postnatal services in the hospital. The services sought by the HIV positive mothers included PMTCT follow up for the HIV exposed babies. Mothers and infants pairs with medical conditions such as hypertension, fever, or malnourished, septic caesarian section wounds (for the mother) were excluded from the study due to their need for higher level care.

\section{Sampling procedures}

Consecutive sampling procedure was used to select participants. In this technique, all mothers-infant pairs who were registered in the clinic and met the recruitment criteria were approached by the research assistant at the triage in the clinic, and had the study explained to them. Upon ascertaining that a mother was eligible in the study, the research assistant also confirmed if she was willing and comfortable to participate in the study by taking her through the informed consent. The women who consented were enrolled into the study until the desired sample size was achieved. Data collection was done through face to face interview using a structured and pre-tested questionnaire.

\section{Blood sample collection}

From each of the participants enrolled, about $4 \mathrm{~mL}$ single draw whole blood sample was collected into ethylamine diamine tetraacetic acid (EDTA) tubes by venom-puncture during their normal visit to the clinic. The same amount of blood (4 $\mathrm{ml})$ was drawn from the HBV-exposed infants by a trained phlebotomist.

Sample separation and storage: This whole blood sample was centrifuged at $10,000 \mathrm{~g}$ for 10 minutes where plasma was separated from the cells and stored at $-80{ }^{\circ} \mathrm{C}$.

Hepatitis B surface antigen rapid test: Initial screening for HBV in all the 534 mothers and the $19 \mathrm{HBV}$ exposed infants was done using HBsAg rapid EME kit (Euromedi Equip ltd. UK). The dipstick rapid strip was dipped into serum/ plasma for 10 seconds and then laid flat on a clean, dry, non- absorbent surface as per the manufacturer's instructions. The results were then read after 15 minutes.

Hepatitis B surface antigen ELISA: Further screening for HBV in all the 534 mothers' samples was done with an ELISA. 19 samples from the HBV exposed infants were also screened using the Hepanostika HBsAg Ultra (France), ELISA kit. In this, a sandwich ELISA involving primary and secondary anti-HBV were used to detect HBV surface antigen in plasma. 25 micro liters $(\mu 1)$ of specimen diluents was assigned into micro Elisa wells. $100 \mu \mathrm{l}$ of undiluted sample was added and incubated at 37 degrees Celsius for 60 minutes. 50 $\mu 1$ of the conjugate solution was added into each well and incubated at 37 degrees Celsius for 60 minutes. Washing was done using the phosphate buffer for six times and $100 \mu 1 \mathrm{TMB}$ substrate added into each well. The plate at this point was incubated at 15 to 30 degree Celsius for 30 minutes in the dark. Thereafter the reaction was stopped by adding sulfuric acid into each well and the plates were read at 450 nm wavelength.

Hepatitis B 'e' antigen ELISA: All the 19 mothers' samples that were $\mathrm{HBsAg}$ positive were subjected to $\mathrm{HBeAg}$ ELISA that was performed using HB'e'Ag Accubiotech Co. Ltd (Beijing, China) ELISA kit. $\mathrm{HBeAg}$ indicates chronic HBV infection with continuous viral shedding thus probability of high HBV DNA viral loads. $50 \mu \mathrm{l}$ of sample was added onto the micro-well plates followed by addition of $50 \mu \mathrm{HRP}$ - conjugate which were mixed gently by tapping as per the manufacturer's instructions. The ELISA plate was then incubated at 37 degrees Celsius, then washed five times using wash buffer. 50 $\mu 1$ chromate was added, incubated in the dark for 15 minutes and 50 micro liter stop solution added. The plate was read at $450 \mathrm{~nm}$.

Hepatitis B virus DNA qualitative PCR for detection of HBV: All the 19 HBsAg ELISA positive samples from the mothers and the 19 samples from the HBV exposed infants were subjected to nucleic acid amplification test (NAAT) to increase the sensitivity. HBV DNA was extracted from $100 \mu 1$ of plasma sample using the QIAamp DNA Mini Kit extraction kit (Qiagen) according to manufacturer's instruction. The PCR was performed using a 96 well cycler (Gene AMP PCR system 9700, applied Biosystems). The preS1 region of the HVB gene was amplified using primers HBPr1 (GGGTCACCATATTCTTGGG) and HBPr135 (CA (A)G)AGACAAAAGAAAATTGG) for the first round PCR followed by a second nested reaction using HBPr2 (GAACAAGAGCTACAGCATGGG) and HBPr3 (CCACTGCATGGCCTGAGGATG) (Stuyver et al. 1999). The first and second PCR reaction was performed with a cycle at $94 \mathrm{OC}$ for $10 \mathrm{~min}$, followed by 40 cycles at $94^{\circ} \mathrm{C}$ for $30 \mathrm{sec}, 50^{\circ} \mathrm{C}$ for $30 \mathrm{sec}$ and $72{ }^{\circ} \mathrm{C}$ for $1 \mathrm{~min}$, with a final extension of $72{ }^{\circ} \mathrm{C}$ for $10 \mathrm{~min}$. Amplicons (1microlitre) were analyzed by electrophoresis on $1.5 \%$ agarose gels, stained with Ethidium bromide and visualized on a UV trans illuminator. The resulting DNA fragments were visible as clearly defined bands. A DNA standard ladder was used for the determination of the sizes of the sample bands.

\section{Statistical analysis}

Statistical analysis was conducted using SPSS version 21. The prevalence of $\mathrm{HBV}$ in mothers was presented as a proportion with $95 \% \mathrm{CI}$. HBV transmission to infants was calculated as the proportion of infants of HBV-infected mothers with HBV infection. Factors associated with HBV infection were analyzed using independent $t$ test to compare mean age between those mothers infected and those not infected. In addition categorical variables such as marital status, previous HBV testing, number of sexual partners, mode of delivery, history of blood transfusion, dental surgery, body piercing, use of HAART, adherence to antiretroviral therapy (ART) drug and substance use, HBV vaccination and mother's job occupation were associated with $\mathrm{HBV}$ infection using Chi-square test of association. All statistical tests were interpreted at $5 \%$ level of significance $(95 \%$ CI).

\section{Ethical considerations}

The study protocol and the informed consent were reviewed and approved by the Kenya Medical Research Institute Scientific and Ethics Review Unit (SERU), and the University of Nairobi/ Kenyatta National Hospital Ethics and Review Committee (ERC).

\section{Results}

Five hundred and thirty-four (534) HIV positive mothers who were enrolled in PMTCT and 19 HBV exposed infants were enrolled in this study. The children had a median age of 6 months and $61.2 \%$ of them were females. The mean age of the mothers was 31.2 years (SD 5.4 years) ranging between 18 and 45 years? 433 (81.1\%) were married, $272(50.9 \%)$ had tertiary level of education, $318(59.5 \%)$ were employed and $99.1 \%$ were Christians.

\section{Risk profile of HBV}

Among the mothers interviewed, $12.4 \%$ disclosed substance use, $12 \%$ used alcohol, $1.1 \%$ cigarettes and 2 mothers $(0.4 \%)$ reported 
using hard drugs. The women had a mean age at first sexual intercourse of 17.5 years (SD 1.9 years). Condom use was very high at $99.8 \%$ and $92.7 \%$ of the mothers had a single sexual partner. Some of the mothers (4.9\%) reported a history of blood transfusion and 5.2\% had ever received body piercing. History of dental surgery was reported in $10.3 \%$ of the cases (Tables 1-4).

Table I Baseline Characteristics

\begin{tabular}{|c|c|}
\hline $\begin{array}{l}\text { Variable } \\
\text { Age of the mothers }\end{array}$ & Frequency (\%) \\
\hline Mean (SD) & $31.2(5.4)$ \\
\hline Min-max & $18.0-45.0$ \\
\hline \multicolumn{2}{|l|}{ Age of child in months } \\
\hline Median (IQR) & $6.0(3.0-10.0)$ \\
\hline Min-max & $1.5-18.0$ \\
\hline \multicolumn{2}{|l|}{ Gender of children } \\
\hline Male & $207(38.8)$ \\
\hline Female & $327(6 \mid .2)$ \\
\hline \multicolumn{2}{|l|}{ Marital status } \\
\hline Not married & $101(18.9)$ \\
\hline Married & $433(81.1)$ \\
\hline \multicolumn{2}{|l|}{ Education } \\
\hline Primary and below & 74 (13.9) \\
\hline Secondary & $188(35.2)$ \\
\hline Tertiary & $272(50.9)$ \\
\hline \multicolumn{2}{|l|}{ Occupation } \\
\hline Employed & $318(59.5)$ \\
\hline Unemployed & $216(40.5)$ \\
\hline \multicolumn{2}{|l|}{ Religion } \\
\hline Christian & $529(99.1)$ \\
\hline Muslim & $5(0.9)$ \\
\hline \multicolumn{2}{|l|}{ Substance use } \\
\hline Alcohol & $64(12.0)$ \\
\hline Cigarettes & $6(1.1)$ \\
\hline Hard drugs & $2(0.4)$ \\
\hline \multicolumn{2}{|l|}{ Age at first sexual intercourse } \\
\hline Mean (SD) & $17.5(1.9)$ \\
\hline Min-max & $14.0-25.0$ \\
\hline Use of condoms & $533(99.8)$ \\
\hline Ever received blood transfusion & $26(4.9)$ \\
\hline Body piercing & $28(5.2)$ \\
\hline Dental surgery & $55(10.3)$ \\
\hline \multicolumn{2}{|l|}{ Number of sexual partners } \\
\hline I & $495(92.7)$ \\
\hline 2 & $26(4.9)$ \\
\hline 3 & $12(2.2)$ \\
\hline 6 & I $(0.2)$ \\
\hline Use of HAART & $534(100.0)$ \\
\hline TDF/3TC/NVP & $502(94.0)$ \\
\hline AZT/3TC/NVP(or EFV) & $32(6.0)$ \\
\hline
\end{tabular}

HBV laboratory results

Out of the total 534 mothers, 19 had a positive HBsAg results with both rapid and ELISA techniques. 12 of the 19 samples that tested positive with ELISA also gave positive results on PCR. All the HBsAg positive samples by ELISA were negative for HBeAg. All the $19 \mathrm{HBV}$ exposed infants were negative for HBsAg by rapid ELISA and PCR techniques.

Table 2 HBV Laboratory Results

\begin{tabular}{lllll}
\hline & $\begin{array}{l}\text { HBsAg positive } \\
\text { Rapid }\end{array}$ & ELISA & $\begin{array}{l}\text { HBV DNA PCR } \\
\text { positive }(\mathrm{n}=19)\end{array}$ & $\begin{array}{l}\text { HBeAg ELISA } \\
\text { positive }(\mathrm{n}=19)\end{array}$ \\
\hline Mothers $(\mathrm{n}=534)$ & $\mathrm{I} 3(2.4 \%)$ & $19(3.6 \%)$ & $12(63.2 \%)$ & 0 \\
Infants $(\mathrm{n}=19)$ & 0 & 0 & 0 & 0 \\
\hline
\end{tabular}

HBV prevalence and the level of awareness among mothers

The prevalence of $\mathrm{HBV}$ was $3.6 \%(95 \% \mathrm{Cl} 2.1-5.2 \%)$. $113(21.2 \%)$ of the mothers were aware of HBV infection and only 2 mothers $(0.4 \%)$ had ever been vaccinated for HBV. Mothers who had ever been talked to by a doctor about HBV were $21.3 \%$.
Table 3 HBV Prevalence and Level of Awareness

\begin{tabular}{ll}
\hline Variable & Frequency (\%) \\
\hline HBV infection & $19(3.6)$ \\
HBV awareness & $113(21.2)$ \\
HBV vaccination & $2(0.4)$ \\
Doctor ever talked about HBV & $114(21.3)$ \\
\hline
\end{tabular}

Factors associated with HBV infection

Prevalence of HBV was $9.1 \%$ in patients who had undergone dental surgery compared to $2.9 \%$ in those with no history of dental surgery, OR $3.3(95 \% \mathrm{Cl}$ I.I-9.6), $\mathrm{p}=0.036$.

Table 4 Factors associated with HBV infection

\begin{tabular}{|c|c|c|c|c|}
\hline \multirow[t]{2}{*}{ Variable } & \multicolumn{2}{|c|}{ HBV infection } & \multirow[t]{2}{*}{ OR $(95 \% \mathrm{Cl})$} & \multirow[t]{2}{*}{ P value } \\
\hline & $\begin{array}{l}\text { Positive } \\
(n=19)(\%)\end{array}$ & $\begin{array}{l}\text { Negative } \\
(n=515) n(\%)\end{array}$ & & \\
\hline \multicolumn{5}{|c|}{ Median age of infants in months } \\
\hline (IQR) & $4(2-9)$ & $6(3-10)$ & - & 0.309 \\
\hline \multicolumn{5}{|c|}{ Gender for infants } \\
\hline Male & $5(2.4)$ & $202(97.6)$ & $0.6(0.2-1.6)$ & 0.257 \\
\hline Female & $14(4.3)$ & $3 \mid 3(95.7)$ & 1 & \\
\hline $\begin{array}{l}\text { Mean age of the } \\
\text { mother (SD) } \\
\text { Marital status }\end{array}$ & $31.4(5.2)$ & $31.2(5.4)$ & - & 0.891 \\
\hline Single & $0(0.0 \%)$ & $82(100.0 \%)$ & - & 0.068 \\
\hline Married & $17(3.9 \%)$ & $416(96.1 \%)$ & 1 & \\
\hline $\begin{array}{l}\text { Divorced/separate } \\
\text { Widowed }\end{array}$ & 2 (I0.5\%) & 17 (89.5\%) & $2.9(0.6-13.5)$ & 0.161 \\
\hline \multicolumn{5}{|l|}{ Religion } \\
\hline Christian & $19(3.6 \%)$ & $510(96.4 \%)$ & - & I \\
\hline Muslim & $0(0.0 \%)$ & $5(100.0 \%)$ & & \\
\hline \multicolumn{5}{|l|}{ Education } \\
\hline None & $0(0.0 \%)$ & I (I00.0\%) & - & $\mathrm{I}$ \\
\hline Primary & $3(4.1 \%)$ & 70 (95.9\%) & I. $3(0.3-4.7)$ & 0.74 \\
\hline Secondary & 7 (3.7\%) & 181 (96.3\%) & I.I (0.4-3.I) & 0.811 \\
\hline Tertiary & 9 (3.3\%) & $263(96.7 \%)$ & 1 & \\
\hline \multicolumn{5}{|l|}{ Occupation } \\
\hline Employed & $4(2.5 \%)$ & I 58 (97.5\%) & 1 & \\
\hline Business & $9(5.8 \%)$ & I 47 (94.2\%) & $2.4(0.7-8.0)$ & 0.137 \\
\hline Unemployed & $5(2.7 \%)$ & 177 (97.3\%) & I.I (0.3-4.2) & 0.872 \\
\hline Student & I (2.9\%) & 33 (97.I\%) & $1.2(0.1-\mid \mathrm{I} . \mathrm{I})$ & 0.874 \\
\hline \multicolumn{5}{|l|}{ Substance use } \\
\hline Yes & $5(7.6 \%)$ & 61 (92.4\%) & $2.7(0.9-7.6)$ & 0.072 \\
\hline No & 14 (3.0\%) & $454(97.0 \%)$ & 1 & \\
\hline \multicolumn{5}{|l|}{ Transfusion } \\
\hline Yes & $2(7.7 \%)$ & 24 (92.3\%) & $2.4(0.5-11.0)$ & 0.235 \\
\hline No & 17 (3.3\%) & 491 (96.7\%) & 1 & \\
\hline \multicolumn{5}{|l|}{ Body piercing } \\
\hline Yes & I (3.6\%) & 27 (96.4\%) & I.0 (0.1-7.8) & $\mathrm{I}$ \\
\hline No & $18(3.6 \%)$ & $488(96.4 \%)$ & $\mathrm{I}$ & \\
\hline \multicolumn{5}{|l|}{ HBV awareness } \\
\hline Yes & 5 (4.4\%) & 108 (95.6\%) & I.3 (0.5-3.8) & 0.57 \\
\hline No & 14 (3.3\%) & 407 (96.7\%) & 1 & \\
\hline \multicolumn{5}{|l|}{ HBV vaccination } \\
\hline Yes & $0(0.0 \%)$ & 2 (100.0\%) & $1.0(1.0-1.1)$ & I \\
\hline No & $19(3.6 \%)$ & $513(96.4 \%)$ & I & \\
\hline \multicolumn{5}{|l|}{ Partners } \\
\hline I & $18(3.6 \%)$ & 477 (96.4\%) & $0.7(0.1-5.4)$ & I \\
\hline 2 or more & I (3.8\%) & 38 (96.2\%) & 1 & \\
\hline \multicolumn{5}{|l|}{ Dental surgery } \\
\hline Yes & $5(9.1 \%)$ & 50 (90.9\%) & $3.3(1.1-9.6)$ & 0.036 \\
\hline No & 14 (2.9\%) & 465 (97.1\%) & $\mathrm{I}$ & \\
\hline
\end{tabular}




\section{Discussion}

Our study revealed an HBV infections rate of 3.6\% among HIVinfected women enrolled for PMTCT and receiving effective HIV HAART at the KNH in Nairobi, Kenya. WHO classifies this region as intermediate endemicity (with HBV prevalence ranging between 2 and 7\%). ${ }^{11,12}$ Our results agree with results from similar studies which reported HBV infection prevalence of $2.8 \%$ among HIV positive pregnant women. ${ }^{3}$ And $4 \% \mathrm{HBV}$ infection prevalence among HIV-infected delivering women in Malawi. ${ }^{13}$ Studies in Nigeria and Ethiopia reported higher prevalence of HBV-HIV co-infection at $9.5 \%,{ }^{14}$ and $19 \% .{ }^{2}$ Respectively A study from Southern Ethiopia reported HBV infection prevalence of $0.6 \%$ among HIV-infected pregnant women. ${ }^{15}$ It is notable that a higher HBV prevalence has been reported in the general population with studies in Kenya showing up to $8.8 \%$ prevalence with urban areas reporting ranges between 8 and $30 \% .{ }^{1}$ HBV prevalence among HIV negative pregnant women was reported at 5.6\%. ${ }^{3}$ This was also higher than the prevalence reported in this study. Variations in the prevalence of the HBsAg across studies reflect the demographic and possibly exposure differences within HIV-infected populations.

Vertical transmission of HBV infections has been confirmed in other studies to be influenced by hepatitis B ' $\mathrm{e}$ ' antigen status (HBeAg) which is associated with high HBV DNA viral load. ${ }^{16}$ In our study all samples positive for HBsAg were negative for $\mathrm{HBeAg}$, revealing a possibility of low HBV viral loads in the samples, and thus also contributing to zero transmission. All mothers were on effective first line HAART for managing HIV and had undetectable levels of HIV RNA viral loads. Mothers who were HBV-infected were on Tenofovir (TDF) and Lamivudine (3TC) based regimen; which are also recommended by WHO for management of HBV infections. ${ }^{17}$ The use of TDF and 3TC regimen in this population could have potentially caused the negative status of $\mathrm{HBeAg}$ and hence the possible suppression of HBV DNA viral load. This could have minimized the transmission of HBV to the exposed infants.

The present Kenyan prevention program regarding HBV consists of vaccination against the virus. ${ }^{18}$ The primary hepatitis $\mathrm{B}$ immunization series conventionally consists of three doses of vaccine which include one mono-valent dose at 6 weeks followed by two mono-valets or combined vaccine doses at 10 and 14 weeks respectively. ${ }^{18}$ All the HBV exposed infants had received at least one or all of the doses and this could have attributed to the zero transmission due to the passive immunity. In this study, mothers who had undergone dental surgery had a higher prevalence of HBV infection. This group was 3.3 times more likely to be HBsAg positive compared to the mothers who did not have history of dental surgery. Similar findings were reported in Ethiopia where pregnant mothers who had undergone dental procedure were 2 times as likely to be HBV-infected. ${ }^{19}$ Though statistically not significant, mothers with a history of blood transfusion had a higher prevalence $(7.7 \%)$ compared to $3.3 \%$ in those who had no transfusion. Significant associations have been reported in other studies where one study reported a higher proportion of $\mathrm{HBV}$-infected patients having history of blood transfusion (6.6\%) compared to $2.2 \%$ in those who were HBV negative..$^{20}$ Also, a study in Ethiopia found out that pregnant women who had a history of blood transfusion were 3.7 times more likely to be $\mathrm{HBV}$-infected. ${ }^{2}$ Body piercing and tattooing have been reported in studies to be significantly associated with HBV infection with participants having 3 and 5.7 times respectively the chance of HBV infection. ${ }^{2}$ Our study did not show relationship between education and HBV infection. However, illiteracy has been shown to be associated HBV infection indicating lack of public health awareness/education amongst mothers. ${ }^{19}$ Similarly, intravenous drug users (IDUs) were reported in a study to have a higher risk of HBV infection with HBsAg positivity of $9.6 \%$ in HIV-infected IDUs compared $3.6 \%$ in HIV-infected non-IDUs. ${ }^{9}$ However, our study did not find any significant association between substance use and HBV infection. Due to the similar modes of transmission for HBV and HIV, the number of partners was also considered though it was not statistically significant in this study.

\section{Conclusion}

HBV infection was detected in mothers on HIV postnatal follow up. However there was no $\mathrm{HBV}$ transmission detected between mothers and their children. In this population of HIV-infected pregnant mothers, our observations suggest that the HAART regimen received by them may have prevented vertical transmission of HBV infections to exposed infants.

\section{Study limitations}

Quantitative HBV DNA viral load among the infected mothers was not determined and viral load status was only based on mothers $\mathrm{HBeAg}$ status due to lack of resources. Absence of vital information regarding which viral infection did the mother acquired first between $\mathrm{HBV}$ and HIV was also a limitation.

\section{Recommendations}

HBV screening should be implemented in our PMTCT programs on routine basis. HBV vaccination and immunization among HBV negative mother infant pair should be carried out. We also recommend further studies on occult HBV among HIV-infected mothers.

\section{Acknowledgments}

None.

\section{Conflicts of interest}

None.

\section{References}

1. Guidelines for the treatment of chronic HBV and HCV infections in Kenya, WHO. 2015.

2. Zenebe Y, Mulu W, Yimer M, et al. Sero-prevalence and risk factors of hepatitis B virus and human immunodeficiency virus infection among pregnant women in Bahir Dar city, Northwest Ethiopia. BMC Infect Dis. 2014; 14:14-118.

3. Kilonzo M K. A comparative study of prevalence of hepatitis B among HIV positive and HIV negative pregnant women in Kenyatta National hospital, University of Nairobi library, Kenya. 2014.

4. AVERT. HIV and AIDS in Kenya. Global information and education on HIV and AIDS, Kenya. 2015.

5. Nyirenda M, Beadsworth MB, Stephany P, et al. Prevalence of infection with hepatitis $B$ and $C$ virus and coinfection with HIV in medical inpatients in Malawi. J Infect. 2008;57(1):72-77.

6. Alter MJ. Epidemiology of viral hepatitis and HIV co-infection. $J$ Hepatol. 2006;44(1 Suppl):S6-S9.

7. Noubiap JJ, Nansseu JR, Ndoula ST, et al. Prevalence, infectivity and correlates of hepatitis B virus infection among pregnant women in a rural district of the Far North Region of Cameroon. BMC Public Health. 2015; $15: 454$.

8. Mave V, Kadam D, Kinikar A, et al. Impact of maternal Hepatitis B virus co-infection on mother to child Transmission of HIV. HIV Med. 2014;15(6):347-354. 
9. Webale MK, Budambula V, Lihana R, et al. Hepatitis B virus seroprofiles and genotypes in HIV-1 infected and non infected injection and Non-injection drug users from coastal Kenya. BMC Infect Dis. 2015; 15:373.

10. Wiseman E, Fraser MA, Holden S, et al. Perinatal transmission of hepatitis B virus: an Australian experience. Med J Aust. 2009;190(9):489-492.

11. Abebe A, Nokes DJ, Dejene A, et al. Sero epidemiology of HBV in Addis Ababa, Ethiopia: transmission patterns and vaccine control. Epidemiol Infect. 2003;131(1):757-770.

12. Weekly epidemiological record, World Health Organization. 2009;5(84):405-420.

13. Chasela CS, Kourtis AP, Wall P, et al. Hepatitis B virus infection among HIV-infected pregnant women in Malawi and transmission to infants. $J$ Hepatol. 2015;60(3):508-514.

14. PennapGR, Osanga, ET, Ubam A. Seroprevalence of HBsAg among pregnant women attending antenatal clinic in fedral medical centre in Keffi, Nigeria. Research Journal of Med Sciences. 2011;5(2):80-82.

15. Ramos JM, Toro C, Reyes F, et al. Seroprevalence of HIV-1, HBV, HTLV and Treponema pallidum among pregnant women in rural hospital in Southern Ethiopia. J Clin Virol. 2011;51(1):83-85.
16. Kfutwah AK, Tejiokem MC, Njouom R. A low proportion of $\mathrm{HBeAg}$ among HBsAg- positive pregnant women with known HIV status could suggest low perinatal transmission of HBV in Cameroon. Virol J. 2012;9:62.

17. World Health Organization. Prevention and control of viral hepatitis infection. Framework for Global Action. 2012p.28.

18. EPI protocol for assessing prevalence of Hepatitis B infection in antenatal patients. Immunization Practices Advisory Committee, World Health Organization. 1996;39(no S-2):4

19. Mohammed Awole, Solomon Gebre-Selassie, Seroprevalence of HBsAg and its risk factors among pregnant women in Jimma, Southwest Ethiopia. Ethiop J Health Dev. 2005;19(1):45-50.

20. Zahran KM, Badary MS, Agban MN, et al. Pattern of hepatitis virus infection among pregnant women and their newborns at the Women's Health Center of Assiut University, Upper Egypt. Int J Gynaecol Obstet. 2010;111(2):171-174. 